\title{
Nükleer Tıp Teknikerinin Sahip Olması Gereken Nitelikler
}

\author{
Expected Qualifications for a Nuclear Medicine Technologist
}

Murat BALIKÇI*, M. Hakan ALBAYRAK*, H. Turgut TUROĞLU**, Meral HİÇÜRKMEZ**

ÖZ

$\mathrm{Bu}$ çalışma, nükleer tıp teknikerinin sahip olması gereken bilgi, beceri ve niteliklerin belirlenmesi, konuyla ilgili olarak sektörün ihtiyaçlarının ortaya konulması, mesleki teorik ve pratik bilgideki eksikliklerin belirlenmesi amacıyla yapılmıştır. Ayrıca bu araştırmada, nükleer tıp uzmanlarının ve nükleer tıp fizikçilerinin nükleer tıp teknikerinden beklentilerini ortaya koymak ve bu beklentileri karşılayabilecek meslek standartlarının oluşturulmasına yardımcı olacak çözümlerin bulunması amaçlanmıştır.

Araştırmada veri toplama aracı olarak anket formu kullanılmıştır. Araştırmamıza katılan kişiler tarafından, nükleer tıp teknikerinin görev ve sorumlulukları açısından özellikle nükleer tıp çekim tekniklerine görüntüleme yöntemlerine, radyofarmasi ve kalite kontrole hâkim olması gerektiği ifade edilmiştir. Ayrıca nükleer tıp teknikerinin okul döneminde almış olduğu eğitimin yeterli olmadığı belirtilmiştir. Tıbbi görüntüleme teknikleri programlarının eğitim öğretim süresinin uzatılması ve eğitimöğretim süresince temel teorik bilgilerin verilmesinden sonra son y1l mesleki branşlaşmaya gidilmesi gerektiği ifade edilmiştir. Nükleer tıp teknikerliğinin bir meslek dalı olarak meslek tanımının yapılması ve meslek standartlarının oluşturulması gerektiği belirtilmiştir. Ayrıca güncel bilgilerin, teknolojik gelişmelerin takibi eğitim-öğretim sırasında edinilen bilgilerin tekrar hatırlanması için sertifika, seminer programlarının ve kongrelerin düzenlenmesi gerektiği vurgulanmıştır.

Anahtar Kelimeler: Sağlık Hizmetleri Meslek Yüksekokulu, Nükleer Tıp Teknikeri

\footnotetext{
Murat BALIKCI (®)

* Marmara Üniversitesi Sağlık Hizmetleri Meslek Yüksekokulu Tıbbi Görüntüleme Teknikleri Programı

** Sağlık Bakanlı̆̆ Marmara Üniversitesi Pendik Eğitim ve Araştırma Hastanesi Nükleer Tip Ana Bilim Dalı

e-posta:muratbalikci@marmara.edu.tr
}

\begin{abstract}
This study was aimed at establishing the knowledge, the capabilities and the qualifications for a nuclear medicine technologist supposed to possess, also to determine the needs and to find out and correct their theoretical and practical knowledges. The research also aimed at exposing the expectations of nuclear medicine specialists and nuclear medicine physicists from nuclear medicine technologists and also to find the solutions to fulfill these expectations so as to help in establishing professional standards.

Survey form was used as data collection tool in the research. All the participants suggested that the nuclear medicine technologists should be well versed with shooting methods, radiopharmacy and quality controls. They also stated that the education of nuclear medicine technicians during the school period is insufficient. They suggested that the study period of the medical imaging techniques programs should be extended so that after giving basic theoretical lessons, the final year should be spent in specializing in different branches. They proposed that nuclear medicine technologist profession should be a professional's branch on its own and should have its own professional standards set. In addition, it was emphasized that certificates, seminar programs and congresses should be organized in order to recall the information acquired during the education, following the up-to-date information, and technological developments.
\end{abstract}

Keywords: Vocational School of Health Services, Nuclear Medicine Technologist

\section{GíRiş}

Nükleer tıp, organizmaya verilen radyonüklidlerin incelenecek organ veya dokudaki dağılımını görüntü halinde saptayarak, organ ya da dokularda meydana gelen patolojileri inceleyen; kliniğe bağlı olarak nükleer tedavileri planlayan, uygulayan bilim dalıdır. Tıp, fizik, biyoloji, eczacılık gibi bilimlerle, nükleer fizik, biyofizik, medikal fizik, radyoloji, radyofarmasi, radyobiyoloji, radyoterapi 
gibi dallar ile iş birliği yapan nükleer tıp multidisipliner bir bilim dalı özelliği göstermektedir. Nükleer tıp alanındaki teknolojik gelişmeler nükleer tıp uzmanının optimum seviyede teşhis ve tedaviyi gerçekleştirme sürecinde nitelikli yardımcı sağlık personeli ihiyacı sonucu "Nükleer Tip Teknikerliğì" mesleğini gündeme getirmiştir $(1,2)$.

2547 sayılı YÖK Yasasının 3. Maddesinin 1 bendinde Meslek Yüksekokulu; "belirli mesleklere yönelik nitelikli insan gücü yetiştirmeyi amaçlayan, yılda iki veya üç dönem olmak üzere iki yıllık eğitim-öğretim sürdüren, önlisans derecesi veren bir yükseköğretim kurumu" olarak tanımlanmaktadır. 2017-2018 yılı YÖK verilerine göre 39 devlet, 36 vakıf üniversitesi olmak üzere SHMYO'ları bünyesinde toplam 75 Trbbi Görüntüleme Teknikleri Programı mevcuttur. 2012-2013 eğitim-öğretim yılından itibaren açılmaya başlanan Nükleer Tıp Teknikleri Programı ise bir devlet, iki vakıf olmak üzere toplam üç üniversitede bulunmaktadır $(3,4)$.

Nükleer Tıp Teknikleri Programı bulunan üniversitelerin (Biruni Üniversitesi, Dokuz Eylül Üniversitesi ve Okan Üniversitesi) web sayfaları incelendiğinde Nükleer Tıp Teknikeri meslek tanımı olarak "Nükleer tıp alanında tanı ve tedavi için radyofarmasötik maddeleri güvenli ve yetkin bir şekilde hazırlayıp kullanabilen, Gamma kamera, SPECT, PET, PET-CT, PET-MRI gibi teknolojik cihazlarda görüntüleme ve görüntülerin işlenmesi işlemlerini yapabilen, radyasyondan korunma ve radyasyon güvenliği konusunda eğitimli, gelişen teknolojiyi sahada uygulayabilecek teknik donanıma sahip, bilgiyi sentezleyebilen, göz ve el koordinasyonunu rahat kullanabilen, sağlık çalışanlarıyla ve hastayla iletişim becerilerini kullanabilen nitelikli teknik eleman” olarak tanımlamışlardır (5-7). Ayrıca Türkiye Nükleer Tip Derneği'nin Nükleer Tip Teknisyen El Kitabı'nın önsözünde Nükleer tıp teknikerleri, radyoaktif bileşiklerin hazırlanmasında, hastaya uygulanmasında, görüntülerin elde edilmesinde ve radyonüklid tedavilerin uygulanmasında, nükleer tıp uzmanlarının en önemli yardımcıları olduğu ve bir nükleer tıp bölümünün uluslararası standartlarda ve güvenli sonuç verebilmesi için nükleer tıp teknikerlerinin doğru ve güncel bilgi birikimine sahip olması, radyasyon ile ilgili çalışma prensiplerini bilmesi, görüntüleme cihazlarının özelliklerini öğrenmesi, uygulama becerilerinin geliştirilmesi gerektiğinden bahsedilmiş̧ir (8).

Mesleki Yeterlilik Kurumu tarafından Sağlik Bakanlı̆̆g'nın 2 Mayıs 2014 tarih ve 29007 sayı ile Resmî Gazete' de yayımlanan Sağlık Meslek Mensuplarıile Sağlık
Hizmetlerinde Çalışan Diğer Meslek Mensuplarının İş Ve Görev Tanımlarına Dair Yönetmelikte Nükleer Tıp Teknikeri ile herhangi bir meslek tanımı yapılmamıştır (9).

2007 yılında Yurt ve arkadaşlarının yaptıkları araştırma ile radyoloji teknikerlerinin sahip olması gereken bilgi, beceri ve nitelikleri belirlemek için sektörün ihtiyaçlarının ve beklentilerinin ortaya konulması ve bu beklentilere yanıt verebilecek mesleki eğitim standartlarının geliştirilmesi amaçlanmıştır. 2007 yılında Güldaş ve arkadaşlarının yaptıkları bir başka araştırmada ise sağlık sektörünün Tıbbi Laboratuvar Teknikerinden beklentilerini ve teknikerin sahip olması gereken bilgi, beceri ve nitelikler ile ilgili görüşlerinin ortaya konması amaçlanmıştır $(10,11)$. Bu düşünceden hareketle Nükleer tıp teknikerliğinin meslek tanımını ve meslek standartlarının belirlenmesi, görev, yetki ve sorumluluklarının, gelişen teknoloji ve kliniğin ihtiyaçlarına bağlı olarak, mesleğin optimum kalitede yapılabilmesi için mevcut durumun incelenmesi, gerekli düzenlemelerin yapılması, eğitim ve öğretimin bu ihtiyaçlara göre belirlenmesi hedeflenmiştir. Bu hedef doğrultusunda planlanan araştırmamızın amacı nükleer tıp teknikerinin sahip olması gereken bilgi, beceri ve niteliklerin belirlenmesi, konuyla ilgili olarak sektörün ihtiyaçlarının ortaya konulması, mesleki teorik ve pratik bilgideki eksikliklerin belirlenmesidir. Ayrıca bu araştırma ile nükleer tıp uzmanlarının ve nükleer tıp fizikçilerinin nükleer tıp teknikerinden beklentilerini ortaya koymak ve bu beklentileri karşılayabilecek meslek standartlarının oluşturulmasına yardımcı olacak çözümlerin bulunması amaçlanmıştır.

\section{GEREÇ VE YÖNTEM}

Araştırmanın evrenini Türkiye'deki üniversite, devlet, özel hastane ve özel görüntüleme merkezlerinde çalışan nükleer tıp teknikerleri, nükleer tıp uzmanları ve nükleer tıp fizikçileri oluşturmaktadır. Literatür taraması sonucunda hazırlanan anket araştırmacı tarafından İstanbul içinde mevcut üniversite, devlet, özel hastane ve görüntüleme merkezlerine giderek, İstanbul dışında ise 1-4 Mayıs 2004 tarihlari arasında İzmir Çeşme'de yapılan Nükleer Tip kongresine katılan katılımcılarla yüzyüze görüşme metodu ile toplam 200 kişiye uygulanmıştır.

Araştırmada veri toplama aracı olarak anket formu kullanılmıştır. Anket üç bölümden oluşmaktadır.

Illk bölümde; ankete katılan nükleer tıp teknikeri/ teknisyeni ve nükleer tıp uzmanlarının yaş, cinsiyet, meslek, 
çalıştığg kurum, mezun olduğu okul, mezun olduğu bölüm, mezuniyet tarihi, meslekte çalışma yılı gibi sosyodemografik özellikleri belirlemeye yönelik sorular bulunmaktadır.

İkinci bölümde ise likert ölçek tipine göre hazırlanmış bir nükleer tıp teknikeri/teknisyeninin bilmesi gereken ve görevini ifa edebilmesi için gerekli olan bilgilerin ne düzeyde bilinmesi gerektiğine yönelik çoktan seçmeli sorular bulunmaktadır.

Üçüncü bölümde ise; nükleer tıp teknikeri/teknisyeninin kendini geliştirebilmesi, meslek standartlarının ve görev tanımlarının yapılması, nükleer tıp teknikeri/teknisyenine verilen eğitimin yeterliliği, eğitim süresi gibi açık uçlu sorularla ankete katılan hedef kitlenin düşüncelerinin öğrenilmesine yönelik sorular bulunmaktadır.

Nükleer tıp teknikeri / teknisyeninin niteliklerinin sınırları belirlemek amacıyla bir model oluşturulmuştur. Oluşturulan bu araştırma modelinde; modelin temel unsurunu oluşturan "mesleki nitelikler" (MS) ile ilgili anket sorusu (29. soru) belirlenmiştir. $\mathrm{Bu}$ temel unsurla ilişkili olduğu düşünülen kişisel nitelikler "yaş, cinsiyet, meslek, çalışılan kurum, mezun olunan okul, mezun olunan bölüm, mezuniyet tarihi ve meslekte çalıșma yılı" (K) gibi bağımsız değişkenlerden (2-9. sorular) oluşmaktadır. Modelin 2. bölümü "Kendini geliştirme ihtiyacı" (KGI) olarak adlandırılan (10-26. sorular) likert ölçek tipine göre hazırlanmış nükleer tıp teknikeri / teknisyeninin bilmesi gereken ve görevini ifa edebilmesi için gerekli olan bilgilerin ne düzeyde bilinmesi gerektiğine yönelik tutum ölçeği sorularını içeren çoktan seçmeli sorulardan oluşmaktadır. "Kendini geliştime ihtiyacı" teorik (T) (10-16. sorular) ve pratik (P) (17-26. sorular) bilgiye ihtiyaç olarak belirlenmiştir. 27. soru ise kendini geliştime ihtiyacı ile ilgili olarak hazırlanan açık uçlu sorudan oluşmaktadır. Modelin 3. bölümünde ise nükleer tıp teknikeri / teknisyenine "verilen eğitimin yeterliliği”"ni (E) ölçmek amacıyla (28-29. soru) hazırlanan sorulardan oluşmaktadır (Şekil 1).

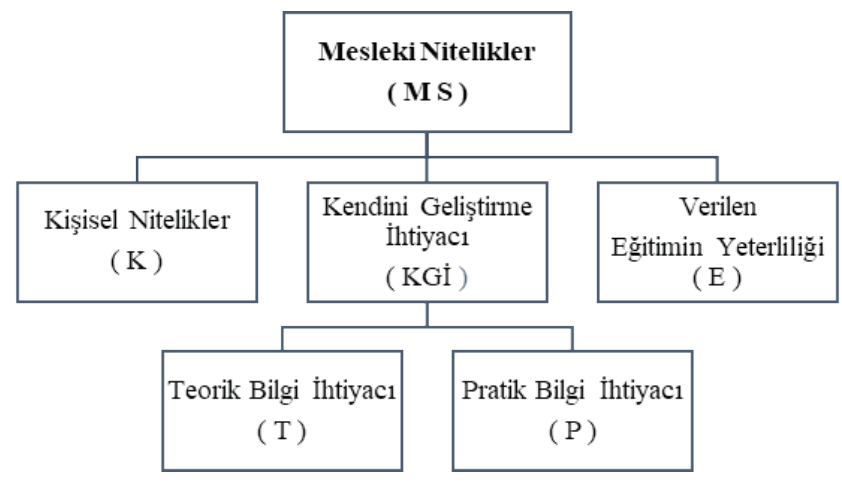

Şekil 1: Nükleer Tıp Teknikeri / Teknisyeninin Niteliklerinin Sınırları Üzerine Araştırma Modeli Yapısı

Veriler analizinde SPSS 13 istatistik programına girildikten sonra analiz edilmiştir. Modelde yer alan kendini geliştirme ile ilgili tutum ölçeğinin hedeflenen konuyu tutarlı ölçüm yapıp yapmadığını belirlemek amacıyla yapılmış olup güvenilirlik analizinde Cronbach Alfa (İç tutarlılık) katsayısından yararlanılmıştır.

\section{BULGULAR}

Çalışmamıza katılan kişilerin sosyodemografik yapısı (anketin birinci bölümü) Tablo 1'de sıklık dağılımları verilmiştir. Nükleer tıp teknikerinin mesleğini optimum seviyede yerine getirebilmesi ile ilgili olarak katılımcıların, temel ve tamamlayıcı bilgiler hakkındaki beklentilerinin sıklık dağılımları Tablo-2a'da; mesleğin teorik bilgiyi kullanarak pratikte sonuç elde edildiği kısmı ile ilgili beklentilerinin sıklık dağılımları Tablo-2b'de ve verilen eğitimin yeterliliği ilgili verdikleri cevaplara göre dağılımları Tablo-2c'de verilmiştir.

Çalışmamıza katılan kişilerin yaşa göre dağılımları \%48'i 30-39, \%32,5'i 18-29, \%15'i 40-49, \%4,5' $\mathrm{i}$ ise 50 ve üstü yaş grubundadır. Çalışmamıza katılan kişilerin \%50'si kadın \%50'si erkektir. Meslek gruplarına göre dağılımları \%50,5'i nükleer tıp uzmanı, \%43,5'i nükleer tıp teknikeri / teknisyeni, \%6'sı ise fizik mühendisidir. Çalıştıkları kuruma göre dağılımları \%48,5'i üniversite hastanesi, \%16's1 özel hastane, \%11,5'i nükleer tıp merkezinde, \%17,5'i devlet hastanesi, \%6,5'i görüntüleme merkezinde çalışmaktadır. Çalışmamıza katılanların \%50,5'i tıp fakültesi, \%37'si sağlık hizmetleri meslek yüksekokulu Tıbbi Görüntüleme Teknikleri programı, \%6'sı fizik bölümü, \%3'ü lise, \%1,5'i sağlık meslek lisesi radyoloji bölümü, \%1,5'i hemşirelik yüksekokulu, \%0,5'i tıbbi laboratuvar teknikleri programı 
mezunudur. Meslekte çalışma yılına göre dağılımları ise \%34'ünün 1-5 y1l, \%24,5'inin 6-10 y11, \%22'sinin 1115 yıl, \%10,5'inin 16-20 yıl ve \%9'unun 20 y1l ve üzeri çalıştı̆̆ görülmektedir (Tablo 1).

Tablo 1: Araştırmaya Katılan Kişilerin Sosyo-Demografik Özellikleri

\begin{tabular}{|c|c|c|c|c|}
\hline $\mathbf{n}$ & Sosyo Demografik Sorular & $\mathbf{n}$ & $\%$ & \begin{tabular}{|l|} 
Toplam \\
$\%$ \\
\end{tabular} \\
\hline \multirow{5}{*}{$\stackrel{\overparen{\pi}}{\stackrel{\pi}{\pi}}$} & \multicolumn{4}{|l|}{ Yaş } \\
\hline & $18-29$ & 65 & 32,5 & 32,5 \\
\hline & $30-39$ & 96 & 48 & 80,5 \\
\hline & $40-49$ & 30 & 15 & 95,5 \\
\hline & 50 ve üstü & 9 & 4,5 & 100 \\
\hline \multirow{3}{*}{$\stackrel{\mathbb{I}}{\stackrel{\Xi}{=}}$} & \multicolumn{4}{|l|}{ Cinsiyet } \\
\hline & Kadın & 100 & 50 & 50 \\
\hline & Erkek & 100 & 50 & 100 \\
\hline \multirow{4}{*}{ 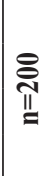 } & \multicolumn{4}{|l|}{ Meslek } \\
\hline & Nükleer Tıp Uzmanı & 101 & 50,5 & 50,5 \\
\hline & Nükleer Tip Teknikeri / Teknisyeni & 87 & 43,5 & 94 \\
\hline & Fizikçi & 12 & 6 & 100 \\
\hline \multirow{6}{*}{ 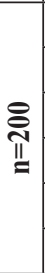 } & \multicolumn{4}{|l|}{ Çalışılan Kurum } \\
\hline & Devlet Hastanesi & 35 & 17,5 & 17,5 \\
\hline & Üniversite Hastanesi & 97 & 48,5 & 66 \\
\hline & Özel Hastane & 32 & 16 & 82 \\
\hline & Görüntüleme Merkezi & 13 & 6,5 & 88,5 \\
\hline & Nükleer Tıp Merkezi & 23 & 11,5 & 100 \\
\hline \multirow{8}{*}{ 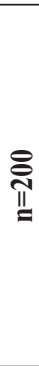 } & \multicolumn{4}{|l|}{ Mezun Olunan Bölüm } \\
\hline & Tıp Fakültesi & 101 & 50,5 & 50,5 \\
\hline & SHMYO Radyoloji (Ön lisans) & 74 & 37 & 87,5 \\
\hline & Sağl1k Meslek Lisesi Radyoloji & 3 & 1,5 & 89 \\
\hline & Lise & 6 & 3 & 92 \\
\hline & Fizik Bölümü & 12 & 6 & 98 \\
\hline & Hemşirelik Yüksekokulu & 3 & 1,5 & 99,5 \\
\hline & Tibbi Laboratuvar & 1 & 0,5 & 100 \\
\hline \multirow{6}{*}{$\underset{\mathbb{\pi}}{\stackrel{\Xi}{=}}$} & \multicolumn{4}{|l|}{ Meslekte Çalışma Yılı } \\
\hline & $1-5 \mathrm{y} 1 \mathrm{l}$ & 68 & 34 & 34 \\
\hline & $6-10$ y1l & 49 & 24,5 & 58,5 \\
\hline & $11-15$ y1l & 44 & 22 & 80,5 \\
\hline & $16-20 \mathrm{y} 1 \mathrm{l}$ & 21 & 10,5 & 91 \\
\hline & 20 y1l ve üzeri & 18 & 9 & 100 \\
\hline
\end{tabular}

Çalışmamıza katılan katılımcıların \%50'si tıbbi terminolojiyikesinliklebilmesi gerektiğini, \%49'u anatomiyi kesinlikle bilmesi gerektiğini, \%43,5'i fizyoloji bilmesinin yararlı olduğunu, \%51,5'i farmakolojiyi bilmesinin yararlı olduğunu, \%49,5'i EKG bilmesinin yararlı olduğunu, \%53'ü yabancı dil bilmesinin yararlı olduğunu, \%44,5'i bilgisayar bilmesi gerektiğini ifade etmişlerdir (Tablo 2-a).
Tablo 2-a: Ankete Katılan Kişilerin "Nükleer Tıp Teknikeri / Teknisyeninin Bilgi, Beceri Ve Niteliklerinin Belirlenmesi” İle İlgili Beklenti Düzeylerine Göre Dağılımları

\begin{tabular}{|c|c|c|c|c|}
\hline \multicolumn{2}{|c|}{$\begin{array}{l}\text { Sizce nükleer tıp teknikeri / } \\
\text { teknisyeninin tıbbi terminoloji } \\
\text { bilmesi gerekir mi? }\end{array}$} & Sayı & $\%$ & Toplam \% \\
\hline \multirow{3}{*}{ 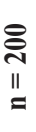 } & Bilmesi yararlı olur & 23 & 11,5 & 11,5 \\
\hline & Bilmesi gerekir & 77 & 38,5 & 50,0 \\
\hline & Kesinlikle bilmesi gerekir & 100 & 50,0 & 100,0 \\
\hline \multicolumn{5}{|c|}{$\begin{array}{l}\text { Sizce nükleer tıp teknikeri / teknisyeninin Anatomi bilmesi } \\
\text { gerekir mi? }\end{array}$} \\
\hline \multirow{4}{*}{$\begin{array}{l}\underset{\text { స్ }}{\|} \\
=\end{array}$} & Bilmesi gerekmez & 2 & 1,0 & 1,0 \\
\hline & Bilmesi yararlı olur & 36 & 18,0 & 19,0 \\
\hline & Bilmesi gerekir & 64 & 32,0 & 51,0 \\
\hline & Kesinlikle bilmesi gerekir & 98 & 49,0 & 100,0 \\
\hline
\end{tabular}

Sizce nükleer tıp teknikeri / teknisyeninin Fizyoloji bilmesi gerekir mi?

\begin{tabular}{|c|c|c|c|}
\hline Bilmesi gerekmez & 20 & 10,0 & 10,0 \\
\hline Bilmesi yararlı olur & 87 & 43,5 & 53,5 \\
\hline Bilmesi gerekir & 56 & 28,0 & 81,5 \\
\hline Kesinlikle bilmesi gerekir & 37 & 18,5 & 100,0 \\
\hline
\end{tabular}

Sizce nükleer tıp teknikeri / teknisyeninin Farmakoloji bilmesi

\begin{tabular}{|l|l|r|r|r|}
\multicolumn{5}{|c|}{ gerekir mi? } \\
\hline \multirow{2}{*}{$\underset{\sim}{\stackrel{4}{*}}$} & Kesinlikle gerekmez & 2 & 1,0 & 1,0 \\
\cline { 2 - 5 } & Bilmesi gerekmez & 39 & 19,5 & 20,5 \\
\cline { 2 - 5 } & Bilmesi yararlı olur & 103 & 51,5 & 72,0 \\
\cline { 2 - 5 } & Bilmesi gerekir & 34 & 17,0 & 89,0 \\
\cline { 2 - 5 } & Kesinlikle bilmesi gerekir & 22 & 11,0 & 100,0 \\
\hline
\end{tabular}

Sizce nükleer tıp teknikeri / teknisyeninin EKG bilmesi gerekir mi?

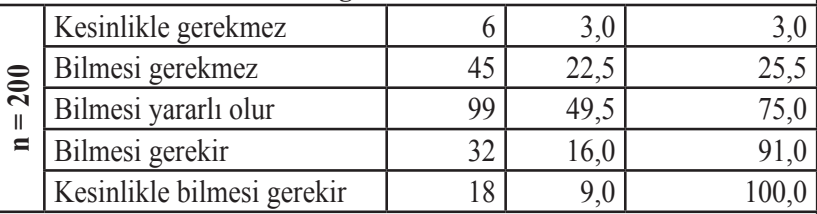

Sizce nükleer tıp teknikeri / teknisyeni yabancı dil bilmesi gerekir mi?

\begin{tabular}{l|l|r|r|r|}
\hline \multirow{2}{*}{$\underset{N}{*}$} & Kesinlikle gerekmez & 2 & 1,0 & 1,0 \\
\cline { 2 - 5 } & Bilmesi gerekmez & 5 & 2,5 & 3,5 \\
\cline { 2 - 5 } & Bilmesi yararlı olur & 106 & 53,0 & 56,5 \\
\cline { 2 - 5 } & Bilmesi gerekir & 67 & 33,5 & 90,0 \\
\cline { 2 - 5 } & Kesinlikle bilmesi gerekir & 20 & 10,0 & 100,0 \\
\hline
\end{tabular}

Sizce nükleer tıp teknikeri / teknisyeni bilgisayar bilmesi gerekir mi?

\begin{tabular}{|c|c|c|c|c|}
\hline \multirow{5}{*}{ II } & Kesinlikle gerekmez & 1 & 5 & 5 \\
\hline & \multicolumn{4}{|l|}{ Bilmesi gerekmez } \\
\hline & Bilmesi yararlı olur & 31 & 15,5 & 16,5 \\
\hline & Bilmesi gerekir & 89 & 44,5 & 61,0 \\
\hline & Kesinlikle bilmesi gerekir & 78 & 39,0 & 100,0 \\
\hline
\end{tabular}

Çalışmamıza katılan katılımcıların \% 40’1 radyofarmasiyi kesinlikle bilmesi gerektiğini, \%34,5'i radyofarmaside kalite kontrol yöntemlerini bilmesi gerektiğini, \%61,5'i gama kameraların çalışma prensiplerini kesinlikle bilmesi gerektiğini, 
\%83'ü nükleer tıp çekim tekniklerini kesinlikle bilmesi gerektiğini, \%47,5'i nükleer tıp cihazlarında (SPECT) kalite kontrol yöntemlerini kesinlikle bilmesi gerektiğini, \%37,5'i nükleer tıp cihazlarında (PET) kalite kontrol yöntemlerini bilmesi gerektiğini, ifade etmişlerdir (Tablo 2-b).

Tablo 2-b: Ankete Katılan Kişilerin "Nükleer Tıp Teknikeri / Teknisyeninin Bilgi, Beceri Ve Niteliklerinin Belirlenmesi” İle İlgili Beklenti Düzeylerine Göre Dağılımları

\begin{tabular}{|c|c|c|c|c|}
\hline & & n & $\%$ & Toplam \% \\
\hline \multicolumn{5}{|c|}{$\begin{array}{c}\text { Sizce nükleer tıp teknikeri / teknisyeninin Radyofarmasi } \\
\text { yöntemlerini bilmesi gerekir mi? }\end{array}$} \\
\hline \multirow{4}{*}{$\begin{array}{l}\text { ్ㅗㅇ } \\
\text { II } \\
=\end{array}$} & Bilmesi gerekmez & 4 & 2,0 & 2,0 \\
\hline & Bilmesi yararlı olur & 42 & 21,0 & 23,0 \\
\hline & Bilmesi gerekir & 74 & 37,0 & 60,0 \\
\hline & Kesinlikle bilmesi gerekir & 80 & 40,0 & 100,0 \\
\hline \multicolumn{5}{|c|}{$\begin{array}{l}\text { Sizce nükleer tıp teknikeri / teknisyeninin Radyofarmasi'de kalite } \\
\text { kontrol yöntemlerini bilmesi gerekir mi? }\end{array}$} \\
\hline \multirow{5}{*}{$\begin{array}{l}\stackrel{\text { సิ }}{\text { ॥ }} \\
=\end{array}$} & Kesinlikle gerekmez & 2 & 1,0 & 1,0 \\
\hline & Bilmesi gerekmez & 13 & 6,5 & 7,5 \\
\hline & Bilmesi yararlı olur & 55 & 27,5 & 35,0 \\
\hline & Bilmesi gerekir & 69 & 34,5 & 69,5 \\
\hline & Kesinlikle bilmesi gerekir & 61 & 30,5 & 100,0 \\
\hline \multicolumn{5}{|c|}{$\begin{array}{l}\text { Sizce nükleer tıp teknikeri / teknisyeni gamma kameraların çalışma } \\
\text { prensiplerini bilmesi gerekir mi? }\end{array}$} \\
\hline \multirow{4}{*}{$\begin{array}{l}\text { ్ㅗ } \\
\text { ॥ } \\
=\end{array}$} & Bilmesi gerekmez & 2 & 1,0 & 1,0 \\
\hline & Bilmesi yararlı olur & 18 & 9,0 & 10,0 \\
\hline & Bilmesi gerekir & 57 & 28,5 & 38,5 \\
\hline & Kesinlikle bilmesi gerekir & 123 & 61,5 & 100,0 \\
\hline \multicolumn{5}{|c|}{$\begin{array}{c}\text { Sizce nükleer tıp teknikeri / teknisyeni nükleer tıp çekim } \\
\text { tekniklerini bilmesi gerekir mi? }\end{array}$} \\
\hline \multirow{3}{*}{$\begin{array}{l}\stackrel{\text { స }}{1} \\
\text { II } \\
=\end{array}$} & Bilmesi yararlı olur & 3 & 1,5 & 1,5 \\
\hline & Bilmesi gerekir & 31 & 15,5 & 17,0 \\
\hline & Kesinlikle bilmesi gerekir & 166 & 83,0 & 100,0 \\
\hline \multicolumn{5}{|c|}{$\begin{array}{l}\text { Sizce nükleer tıp teknikeri / teknisyeni nükleer tıp cihazlarında } \\
\text { (SPECT) kalite kontrol yöntemlerini bilmesi gerekir mi? }\end{array}$} \\
\hline \multirow{5}{*}{$\begin{array}{l}\stackrel{\sim}{N} \\
\text { II } \\
=\end{array}$} & Kesinlikle gerekmez & 1 &., 5 & .5 \\
\hline & Bilmesi gerekmez & 4 & 2,0 & 2,5 \\
\hline & Bilmesi yararlı olur & 28 & 14,0 & 16,5 \\
\hline & \begin{tabular}{|l} 
Bilmesi gerekir \\
\end{tabular} & 72 & 36,0 & 52,5 \\
\hline & Kesinlikle bilmesi gerekir & 95 & 47,5 & 100,0 \\
\hline \multicolumn{5}{|c|}{$\begin{array}{l}\text { Sizce nükleer tıp teknikeri / teknisyeni nükleer tıp cihazlarında } \\
\text { (PET) kalite kontrol yöntemlerini bilmesi gerekir mi? }\end{array}$} \\
\hline \multirow{5}{*}{$\begin{array}{l}\stackrel{\text { ㄱ }}{1} \\
\text { I }\end{array}$} & Kesinlikle gerekmez & 2 & 1,0 & 1,0 \\
\hline & Bilmesi gerekmez & 16 & 8,0 & 9,0 \\
\hline & Bilmesi yararlı olur & 51 & 25,5 & 34,5 \\
\hline & \begin{tabular}{|l|} 
Bilmesi gerekir \\
\end{tabular} & 75 & 37,5 & 72,0 \\
\hline & Kesinlikle bilmesi gerekir & 56 & 28,0 & 100,0 \\
\hline
\end{tabular}

Çalışmamıza katılan katılımcıların \%58'i görüntü prosesleme tekniklerini kesinlikle bilmesi gerektiğini, \%44,5'i radyonüklid tedavi yöntemlerini bilmesinin yararlı olduğunu, \%50'si radyobiyoloji bilmesinin yararlı olduğunu, \%45,5'i nükleer tıp cihazlarında meydana gelen arızaların sebeplerini bilmesinin yararlı olduğunu ifade etmişlerdir (Tablo 2-c).

Tablo 2-c: Ankete Katılan Kişilerin "Nükleer Tıp Teknikeri / Teknisyeninin Bilgi, Beceri Ve Niteliklerinin Belirlenmesi” İle İlgili Beklenti Düzeylerine Göre Dağılımları

\begin{tabular}{|c|c|c|c|c|}
\hline & & $\mathbf{n}$ & $\%$ & $\begin{array}{l}\text { Toplam } \\
\%\end{array}$ \\
\hline \multicolumn{5}{|c|}{$\begin{array}{c}\text { Sizce nükleer tıp teknikeri / teknisyeni nükleer tıpta kullanılan } \\
\text { görüntü prosesleme yöntemlerini bilmesi gerekir mi? }\end{array}$} \\
\hline \multirow{4}{*}{ 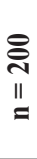 } & Bilmesi gerekmez & 5 & 2,5 & 2,5 \\
\hline & \begin{tabular}{|l} 
Bilmesi yararlı olur \\
\end{tabular} & 21 & 10,5 & 13,0 \\
\hline & \begin{tabular}{|l|} 
Bilmesi gerekir \\
\end{tabular} & 58 & 29,0 & 42,0 \\
\hline & Kesinlikle bilmesi gerekir & 116 & 58,0 & 100,0 \\
\hline \multicolumn{5}{|c|}{$\begin{array}{c}\text { Sizce nükleer tıp teknikeri / teknisyeni radyonüklid tedavi } \\
\text { yöntemlerini bilmesi gerekir mi? }\end{array}$} \\
\hline \multirow{5}{*}{$\begin{array}{l}\text { 글 } \\
\text { II }\end{array}$} & Kesinlikle gerekmez & 18 & 9,0 & 9,0 \\
\hline & Bilmesi gerekmez & 41 & 20,5 & 29,5 \\
\hline & \begin{tabular}{|l|} 
Bilmesi yararli olur \\
\end{tabular} & 89 & 44,5 & 74,0 \\
\hline & Bilmesi gerekir & 34 & 17,0 & 91,0 \\
\hline & Kesinlikle bilmesi gerekir & 18 & 9,0 & 100,0 \\
\hline
\end{tabular}

Sizce nükleer tıp teknikeri / teknisyeni Radyobiyoloji bilmesi gerekir mi?

\begin{tabular}{|c|c|c|c|c|}
\hline \multirow{5}{*}{ 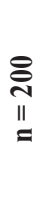 } & Kesinlikle gerekmez & 2 & 1,0 & 1,0 \\
\hline & Bilmesi gerekmez & 19 & 9,5 & 10,5 \\
\hline & Bilmesi yararlı olur & 100 & 50,0 & 60,5 \\
\hline & Bilmesi gerekir & 60 & 30,0 & 90,5 \\
\hline & Kesinlikle bilmesi gerekir & 19 & 9,5 & 100,0 \\
\hline
\end{tabular}

Sizce nükleer tıp teknikeri / teknisyeni nükleer tıp cihazlarında meydana gelen arızaların sebeplerini bilmesi gerekir mi?

\begin{tabular}{|l|l|r|r|r|}
\multirow{2}{*}{$\underset{\bar{N}}{\|}$} & Bilmesi gerekmez & 9 & 4,5 & 4,5 \\
\cline { 2 - 5 }$=$ & Bilmesi yararl1 olur & 91 & 45,5 & 50,0 \\
\cline { 2 - 5 } & Bilmesi gerekir & 68 & 34,0 & 84,0 \\
\cline { 2 - 5 } & Kesinlikle bilmesi gerekir & 32 & 16,0 & 100,0 \\
\hline
\end{tabular}

Sizce nükleer tıp teknikeri / teknisyeni yabancı dil bilmesi gerekir mi?

\begin{tabular}{|c|c|c|c|c|}
\hline \multirow{5}{*}{$\begin{array}{l}\text { స్ } \\
\text { ॥ } \\
=\end{array}$} & Kesinlikle gerekmez & 2 & 1,0 & 1,0 \\
\hline & Bilmesi gerekmez & 5 & 2,5 & 3,5 \\
\hline & Bilmesi yararlı olur & 106 & 53,0 & 56,5 \\
\hline & Bilmesi gerekir & 67 & 33,5 & 90,0 \\
\hline & Kesinlikle bilmesi gerekir & 20 & 10,0 & 100,0 \\
\hline
\end{tabular}

Sizce nükleer tıp teknikeri / teknisyeni bilgisayar bilmesi gerekir

\begin{tabular}{|c|c|c|c|c|}
\hline & \\
\hline \multirow{5}{*}{$\begin{array}{l}\text { ్ㅗ } \\
\text { ॥I } \\
=\end{array}$} & Kesinlikle gerekmez & 1 &, 5 &, 5 \\
\hline & Bilmesi gerekmez & 1 & ,5 & 1,0 \\
\hline & Bilmesi yararli olur & 31 & 15,5 & 16,5 \\
\hline & Bilmesi gerekir & 89 & 44,5 & 61,0 \\
\hline & Kesinlikle bilmesi gerekir & 78 & 39,0 & 100,0 \\
\hline
\end{tabular}

Çalışmamıza katılan katılımcıların nükleer tıp teknikerinin \%71,5'i kesinlikle eğitim programlarına ve 
kongrelere katılması ve meslek derneklerine üye olması gerektiğini, \% 45'i eğitim ve hizmetin standardizasyonu için meslek standartlarının olușturulmasının ve görev tanımlarının yapılmasının gerekli olduğunu, \% 78,5'i nükleer tıp teknikeri / teknisyenlerine verilen eğitimin yeterli olmadığını, \% 47'si Tıbbi Görüntüleme Teknikleri eğitimi üzerine 1-2 yıl arasında ihtisaslaşma olması gerektiğini ifade etmişlerdir (Tablo 3).

Tablo 3: Ankete Katılan Kișilerin "Nükleer Teknikeri/ Teknisyenine Verilen Eğitimin Yeterliliğì” İlgili Verdikleri Cevaplara Göre Dağılımları

\begin{tabular}{|c|c|c|c|c|}
\hline & n & $\%$ & $\begin{array}{l}\text { Toplam } \\
\%\end{array}$ \\
\hline \multicolumn{5}{|c|}{$\begin{array}{c}\text { Sizce nükleer tıp teknikeri / teknisyeni kendini geliştirmesi için } \\
\text { hizmet içi eğitim programlarına, kongrelere katılmalı mı ve meslek } \\
\text { derneklerine üye olmalı mıdır? }\end{array}$} \\
\hline & Kesinlikle katılmalı ve üye olmalıdır. & 143 & 71,5 & 71,5 \\
\hline & Fikrim yok & 6 & 3,0 & 74,5 \\
\hline & $\begin{array}{l}\text { Teknoloji ve güncel bilgilerin takibi } \\
\text { için katılmalıdır. }\end{array}$ & 44 & 22,0 & 96,5 \\
\hline & Gerekli olduğunu düşünmüyorum & 7 & 3,5 & 100,0 \\
\hline \multicolumn{5}{|c|}{$\begin{array}{l}\text { Sizce nükleer tıp teknikeri / teknisyenlerine verilen eğitim yeterli } \\
\text { midir? }\end{array}$} \\
\hline \multirow{3}{*}{$\underset{\substack{\text { II } \\
=}}{=}$} & Yeterli & 27 & 13,5 & 13,5 \\
\hline & Yetersiz & 157 & 78,5 & 92,0 \\
\hline & Fikrim yok & 16 & 8,0 & 100,0 \\
\hline \multicolumn{5}{|c|}{$\begin{array}{c}\text { Sizce nükleer tıp teknikeri / teknisyenlerine verilen eğitim kaç yıl } \\
\text { olmalıdır? }\end{array}$} \\
\hline \multirow{4}{*}{$\begin{array}{l}\text { ్ㅗ } \\
\text { ॥ } \\
=\end{array}$} & $\begin{array}{l}\text { Yüksekokul düzeyinde verilen eğitim } \\
\text { yeterlidir }\end{array}$ & 82 & 41,0 & 41,0 \\
\hline & Yüksekokul düzeyinde 3 yıl yeterlidir & 7 & 3,5 & 44,5 \\
\hline & $\begin{array}{l}\text { Tibbi Görüntüleme Teknikleri eğitimi } \\
\text { üzerine 1-2 y1l ihtisaslaşma olmalıdır }\end{array}$ & 94 & 47,0 & 91,5 \\
\hline & Fikrim yok & 17 & 8,5 & 100,0 \\
\hline
\end{tabular}

Nükleer tıp teknikeri / teknisyeninin niteliklerini belirlemek amacıyla oluşturulan modelin 2. bölümünde yer alan Kendini Geliştirme İsteği ile ilgili tutum ölçeğindeki tüm değişkenlerin hedeflenen konuyu tutarlı ölçüp ölçmediği Cronbach Alfa yöntemiyle belirlenmiştir. Daha sonra bu tutum ölçeği teorik bilgi ve pratik bilgi ihtiyacı olarak alt boyutlarına ayrıldıktan sonra tekrar Cronbach Alfa analizine tabii tutulmuştur. Kendini geliştirme isteği bölümüne ait tutum anketinin tüm değişkenler için yapılan Cronbach Alfa tutarlılık analizi sonucunda $(0,844)$ hedeflenen konuyu tutarlı ölçtüğü görülmüştür. (Ölçüm aracının tutarlı sonuç verdiği söylenebilmesi için $0,70<$ Cronbach Alfa olması gerekmektedir.) (12)

Kendini geliştirme isteği bölümüne ait tutum anketinin teorik bilgi ihtiyacı ile ilgili değişkenler (10-16. sorular) için yapılan Cronbach Alfa tutarlılık analizine göre $(0,745)$ hedeflenen konuyu tutarlı ölçtüğü görülmüştür.

Kendini geliştirme isteği bölümüne ait tutum anketinin pratik bilgi ihtiyacı ile ilgili değişkenler (17-26. sorular) için yapılan Cronbach Alfa tutarlılık analizi sonucunda $(0,779)$ hedeflenen konuyu tutarlı ölçtüğü görülmüştür.

Araştırma modelindeki değişkenlerin modelin temel unsuru olan mesleki nitelikler ile ilişkilerinin belirlenmesi amacıyla modelde yer alan değişkenlerin ölçek tipleri kendini geliştirme dışında diğerlerinin nominal sınıflayıcı ölçek seviyesinde olması nedeniyle mesleki niteliklerin bağımlı değişkeninin diğer tüm değişkenlerle olan ilişkilerini sınıflayıcı ölçek seviyesinde (nominal ölçek) ölçüm imkanı veren Ki-kare analiziyle belirlenmiştir. Analiz sonucunda Şekil 1'de gösterilen modeldeki değişkenlerin yani "Kişisel Nitelikler” (Cinsiyet, Meslek, Çalışılan Kurum, Mezun Olunan Bölüm), "Verilen Eğitimin Yeterliliği" (30,31 sorular) ve "Meslek Standartların Konulması" (28. soru) ile "Mesleki Niteliklerin Sınırları" (29. soru) arasındaki ilişkilerinin anlamlı olmadığı görülmüştür ( $\mathrm{p}>0.05)$.

Çalışmamızın esas araştırma konusu olan "Mesleki Niteliklerin Sınırları (29. soru)" ile "Kendini Geliştirme İsteği” (10-26. sorular) arasında farklılık olup olmadığı ANOVA yöntemiyle belirlenmiştir. Analiz sonucunda kendini geliştirme isteğinin araştırma modelinin temel unsuru olan mesleki niteliklerin sınırları açısından anlamlı bir farklılığın olmadığı görülmüştür ( $\mathrm{p}>0.05)$.

\section{TARTIŞMA}

Literatürde Nükleer tıp teknikerinin görev ve sorumlulukları şu ana başlıklar halinde sınıflandırılmıştır:

i. Hasta Hazırlı̆̆ı: Hastanın bakımı nükleer tıp çekim prosedürlerine göre hazırlanması ve hastanın hayati fonksiyonlarının takibi (EKG, nabız, solunum hızı vb gibi)

ii. Nükleer Tıp Cihazlarının Kalite Kontrolü: Nükleer tıp cihazlarının kalite kontrolü ve gerektiğinde düzeltici işlemlerin yapılması

iii. Nükleer Tıp Çekim Prosedürleri: Nükleer tıp çekim prosedürlerin belirlenmesi, uygulanması ve görüntülerin işlemlenmesi

iv. Radyofarmasötikler: Radyofarmasötiklerin hazırlanmas1, kalite kontrolü ve hastaya uygulanması 
v. Radyonüklid Tedavi: Radyonüklid tedavi ile ilgili prosedürlerin yerine getirilmesine yardımcı olması

\section{vi. Radyasyon Güvenliği ile ilgili Prosedürlerin Yerine} Getirilmesi: Hastanın, hasta yakınlarının, sağlık personelinin radyasyon güvenliğinin sağlanması için gerekli tedbirlerin alınması, radyoaktif materyallerin temini, depolanması, kayıtlarının tutulması, radyoaktif atıkların depolanması, kayıtlarının tutulması ve uygun şekillerde imhası için gerekli prosedürlerin yerine getirilmesi (13-18).

Araştırmamıza katılan katılımcılar tarafından eğitimöğretim süresinin ve içeriğinin yetersiz olduğunu, üniversiteler arasında müfredat uyumsuzlukları bulunduğunu ifade etmişlerdir. 2007 yılında yapılan iki çalışmada da benzer sonuçlar elde edilmiştir. $(10,11)$

Günümüzde ilerleyen teknoloji ile artan modalite ve inceleme tekniği bir ön lisans programı içerisinde tüm tekniklerin eğitim ve öğretimini oldukça güçleştirmektedir. TGT programlarında yer alan Nükleer Tıp dersi teorik 3 saati aşmamakta ve staj uygulamalarında ise bazı öğrenciler nükleer tıp stajı yapmadan TGT programlarından mezun olabilmektedir. TGT programlarında nükleer tıp derslerindeki ve pratik nükleer tıp uygulamaları ile gama kamera, SPECT, ve gelişen teknoloji ile son yıllarda eklenen SPECT/BT, PET/BT, PET/MR gibi modalitelerin her birinin ayrı ayrı fizik prensiplerinin, çekim tekniklerinin, gerek teorik gerekse uygulamalı olarak eğitim ve öğretiminin verilmesi mümkün görünmediğinden eksiklikler ancak çalışma hayatında kapatılmakta ve Nükleer Tıp Teknikerlerinin mesleğe adaptasyonları güçleşmekte ve nükleer tıp sektörünün beklentilerini karşılayamamaktadır.

Son yıllarda SHMYO bünyesinde TGT programından bağımsız olarak açılmaya başlanan NTT ön lisans programı nükleer tıpta kullanılan görüntüleme yöntemlerinin eğitim ve öğretimine ayrılan süreyi arttırmıştır. Bu durum nükleer tıp uzmanlarının ve nükleer tıp fizikçilerinin nükleer tıp teknikerinden yukarıda belirtilen beklentilerin karşılanmasında iyileşme sağlayacağını düşündürmektedir.

Diğer yandan TGT, NTT ve radyoterapi ön lisans programlarının artan modalite, inceleme tekniğine ve ortak derslerine bağlı olarak, birbiriyle bağlantılı bu üç ön lisans programının aynı çatı altında, son iki yılda branşlaşabilecekleri lisans programları haline dönüştürülmeleri bir diğer eğitim modeli olabilir. Eğitim süresinin dört seneye çıkması lisansüstü eğitimin de yolunu açarak ilgili alanlarda akademik personelin yetişmesi için de bir çözüm olabilir. Aynı zamanda Avrupa ve ABD'de bulunan her üç disiplin için eşdeğer programlar dikkate alınarak oluşturulan eğitim modeli ile yükseköğrenimde uluslararası standardizasyon sağlanabilir.

Sağlık Hizmetleri Meslek Yüksekokulları arasındaki müfredatlarda ve ders içeriklerinde 2010 yılından itibaren uygulamaya giren İnsan Kaynaklarının Mesleki Eğitim Yoluyla Geliştirilmesi Projesi (İKMEP) ile genel anlamda birliktelik sağlanmışsa da uygulama dar bir çerçevede kalmıştır. 2016 yılında başlayan Çekirdek Eğitim Programı (ÇEP) çalıştayları ile müfredatlarda ve ders içeriklerinde belirli bir standardın sağlanması için çalışmalar devam etmektedir.

Okullardaki nitelikli akademik personel sayısı artırılmalı, yeterli düzeyde eğitim araç ve gereçleri ile okuma salonu ve kütüphane imkânları artırılarak öğrencinin kendini geliştirme, bilimsel araştırmalar yapma ve kaynaklardan yararlanması sağlanmalıdır.

Aynı zamanda sağlık sektöründe çalışan sağlık personeli olarak acil durumlarda gerekli müdahalenin yapılabilmesi için ilkyardım derslerine ağırlık verilmesi ve mevcut kanunlarda değişiklik yapılarak nükleer tıp teknikeri / teknisyeninin radyofarmasötiklerin enjeksiyonu yapabilmesi konuları tartışılmalı ve konsensus sağlandığı takdirde gereği yapılmalıdır.

Meslektaşlar arası bilgi alışverişi, sosyal kaynaşma, meslek dalının gelişmesi, sosyal hak ve sorumlulukların geliştirilebilmesi için meslek derneği kurulmalıdır. $\mathrm{Bu}$ dernek ilgili kuruşlar tarafından desteklenmelidir.

\section{KAYNAKLAR}

1. Tuncel.E.: Radyonüklid Görüntüleme. Klinik Radyoloji. 1. Bask1, Güneş\&Nobel, Bursa 1994: 88-95.

2. Vardareli E.: Nükleer Tıp'ın Tanımı, İçeriği ve Tarihçesi. Editör: Ürper Y. Nükleer T1p. Anadolu Üniversitesi Açıköğretim Fakültesi Yayınları. No: 362. Eskişehir 1993: 2-12

3. T1bbi Görüntüleme Teknikleri Programı Bulunan Tüm Üniversiteler, https://yokatlas.yok.gov.tr/onlisans-program. php?b=30099 (Erişim tarihi: 30 Eylül 2017)

4. Nükleer Tıp Teknikleri Programı Bulunan Tüm Üniversiteler, https://yokatlas.yok.gov.tr/onlisans-program.php?b=39018 (Erişim tarihi: 30 Eylül 2017)

5. Biruni Üniversitesi Sağlık Hizmetleri Meslek Yüksekokulu, Nükleer Tıp Teknikleri Programı Tanıtımı, http://myo.biruni. edu.tr/index.php/myo-nukleer-tip-teknikleri/ (Erişim tarihi: 30 Eylül 2017) 
6. Dokuz Eylül Üniversitesi Sağlık Hizmetleri Meslek Yüksekokulu, Nükleer Tıp Teknikleri Programı Tanıtımı, http://debis.deu.edu.tr/ders-katalog/2015-2016/tr/ bolum_9660_tr.html (Erişim tarihi: 30 Eylül 2017)

7. Okan Üniversitesi Sağlık Hizmetleri Meslek Yüksekokulu, Nükleer Tıp Teknikleri Programı Tanıtımı, https://www. okan.edu.tr/shmyo/sayfa/4591/nukleer-tip-teknikleri/ (Erişim tarihi: 30 Eylül 2017)

8. Nükleer Tıp Teknisyen Notları Teknisyen El Kitabı, PDF Döküman1, http://www.tsnm.org/assets/images/files/ teknisyen_el_kitabi.pdf (Erişim tarihi: 30 Eylül 2017)

9. Sağlık Meslek Mensupları İle Sağlık Hizmetlerinde Çalışan Diğer Meslek Mensuplarının İş Ve Görev Tanımlarına Dair Yönetmelik, http://www.resmigazete.gov.tr/ eskiler/2014/05/20140522-14.htm (Erişim tarihi: 30 Eylül 2017)

10. Yurt A, Manisalıgil A, Güneli E, Ergör A, Altuntaş EÜ. Sağlık Sektörünün Radyoloji Teknikerlerinden Beklentileri. Fırat Sağlık Hizmetleri Dergisi 2009; 4: 59-70.

11. Güldaş N, Kutluk D, Ergör A. Sağlık Sektörününün Tıbbi Laboratuvar Teknikerinden Beklentileri. Dokuz Eylül Üniversitesi Tıp Fakültesi Dergisi. 2010; 24 (2): 45-55
12. Karagöz Y. Güvenilirlik Analizi. SPSS 23 ve AMOS 23 Uygulamalı İstatistiksel Analizler. 1 Bask1, Ankara, Nobel Akademik Yayınc1lık, 2016: 939-41

13. Jennifer L. Prekeges. The Nuclear Medicine Technology Certification Board 2003 Task Analysis Report. Journal of Nuclear Medicine Technology. 2003; 31(2): 86-91

14. Performance and Responsibility Guidelines for the Nuclear Medicine Technologist (Revision 1998), Journal of Nuclear Medicine Technology, 1998; 26(1): 45-9

15. Fusion Imaging: A News Type of Technologist For a New Type of Technology, Journal of Nuclear Medicine Technology, 2002; 30(4): 201-4, http://tech.snmjournals.org/ content/30/4/201.full (Erişim tarihi: 12 Kasım 2017)

16. Murphy D. Technologist Plan for Nuclear Medicine's Future. Journal of Nuclear Medicine Technology. 1997; 25(2): 127-31

17. Basso D, Clarke M, Deletis L, Dillehay G, Early M, Perry D, Tetrault R, Mehlberg L, Davis R, Loveless V, Keech F. Scope of Practice for Nuclear Medicine Tecnologist 2001. Journal of Nuclear Medicine Technology. 2002; 30(2): 64-6

18. Gagnon A, Deman P, Eckdahl J, Folks R, McSherry B, Natale D, Tauxe EL. Guidlines for Technologist Training in Nuclear Cardiology. Journal of Nuclear Cardiology. 1997; 4(5): 422-5 